\title{
Maternal and neonatal risk factors for early-onset group B streptococcal disease: a case control study
}

This article was published in the following Dove Press journal:

International Journal of Women's Health

25 October 2013

Number of times this article has been viewed

\author{
Hanan M Al-Kadri' \\ Samira S Bamuhair ${ }^{2}$ \\ Sameera M Al Johani ${ }^{3}$ \\ Namsha A Al-Buriki' \\ Hani M Tamim ${ }^{4}$ \\ 'Department of Obstetrics and \\ Gynecology, ${ }^{2}$ Department of Basic \\ Medical Sciences, ${ }^{3}$ Microbiology \\ Division, ${ }^{4}$ Department of Medical \\ Education, College of Medicine, \\ King Saud Bin Abdulaziz University \\ for Health Sciences, King Abdulaziz \\ Medical City, Riyadh, Kingdom \\ of Saudi Arabia
}

Correspondence: Hanan M Al-Kadri King Saud Bin Abdulaziz University for Health Sciences, College of Medicine, King Abdulaziz Medical City, PO Box 57374, Riyadh II574, Riyadh, Kingdom of Saudi Arabia Tel +966 I2520088 ext I36II Fax +966 I2520088 ext I3/28 Email halkadri@gmail.com
Objectives: To identify the prominent maternal and neonatal risk factors associated with early-onset group B streptococcus (EOGBS) disease in neonates and to determine their importance by comparing them with a control group.

Setting: Neonatal unit at King Abdulaziz Medical City, Riyadh, Kingdom of Saudi Arabia. Patients: Cases were infants $<7$ days of age with invasive group B streptococcus (GBS) disease diagnosed between January 1, 2000 and December 31, 2009. Controls were healthy infants born in the same hospital during the same period having the same birth weight and gestational age category.

Main outcome measures: Maternal risk factors for developing EOGBS disease, feto-maternal and neonatal clinical data, their morbidities, mortalities, and length of hospital stay.

Results: A total of 99 cases and 200 controls were included. The majority of cases presented in the first 72 hours of life (62/99 [63.9\%]), of which 87/99 (89.7\%) had at least one clinical risk factor for the development of EOGBS disease. Mothers of neonates with EOGBS disease were more likely to have GBS bacteriuria (odds ratio [OR] 10.76, 95\% confidence interval [CI] 1.24-93.42), infection in the peripartum period (OR 8.92, CI 2.87-27.68), and temperature $\geq 38^{\circ} \mathrm{C}$ (OR 7.10, CI 2.50-20.17). GBS disease was associated with premature rupture of membranes and fetal tachycardia $(P<0.01$ for both). Neonates with EOGBS disease were more likely to have respiratory distress disease and convulsions, require tube feeding, and have longer hospital stays compared with the controls $(P<0.01$ for all). Stepwise multiple logistic regression has identified three risk factors that were associated with the highest tendency for the development of EOGBS disease. These were lack of antenatal attendance $(\mathrm{OR}=0.30$ and CI 0.98-0.88), rupture of membranes (OR $=9.62$ and CI 3.1-29.4), and antibiotic use in labor $(\mathrm{OR}=0.16$ and $\mathrm{CI} 0.38-0.67)$.

Conclusion: A number of maternal risk factors were significantly associated with EOGBS disease. Taking these factors into consideration may result in preventing the occurrence of EOGBS disease, improve maternal and neonatal medical care, decrease their hospital stay, and reduce unnecessary hospital resource utilization.

Keywords: group B streptococcus, neonatal morbidity, maternal morbidity, antenatal screening

\section{Introduction}

Group B streptococcus (GBS) or Streptococcus agalactiae is a gram-positive bacterium that colonizes the human gastrointestinal and genital tracts. GBS is the most frequent bacterial pathogen in neonates. ${ }^{1}$ Maternal colonization is the single most important risk factor for early-onset group B streptococcal (EOGBS) disease (younger than 7 days of age). ${ }^{2,3}$ Vertical transmission of GBS during labor or delivery may result in either 
invasive infection in the neonate during the first week of life or EOGBS disease.

A number of obstetrical factors have been associated with an increased likelihood of EOGBS disease in neonates. ${ }^{4}$ These risk factors include prenatal vaginal and rectal colonization with GBS, premature deliveries (less than 37 weeks of gestation completed), prolonged rupture of membranes, and intrapartum fever. In the US, the incidence of GBS disease is also found to be higher among neonates born to AfricanAmerican mothers ${ }^{5,6}$ and to mothers less than 20 years of age. ${ }^{3,6}$ Moreover, neonates born to mothers with a history of birth of a neonate with GBS disease, ${ }^{7}$ those with maternal heavy colonization (such as that seen with bacteriuria [growth of $\geq 100,000$ colony-forming units $/ \mathrm{mL}$ of a single uropathogenic bacteria]), ${ }^{8-12}$ and a low level of anti-GBS capsular antibody ${ }^{13}$ are more likely to be infected.

The most effective method for EOGBS disease prevention is intrapartum antibiotic (IPA). In the 1996 Centers for Disease Control and Prevention guidelines, women at risk were identified through risk-based screening for maternal factors or a microbiological screening in order to identify GBS carriers. ${ }^{14}$ In 2002, Centers for Disease Control and Prevention revised guidelines were issued for the prevention of perinatal invasive GBS diseases..$^{13,15}$ These guidelines have indicated that any pregnant woman with a positive screening culture from either the vagina or rectum has to receive IPA unless a planned cesarean delivery is performed. Moreover, all pregnant women who gave birth to a previous infant with invasive GBS disease, those with documented GBS bacteriuria during the current pregnancy, pregnant women with preterm labor whose GBS culture status is unknown, pregnant women whose amniotic membranes have ruptured for $\geq 18$ hours, and those with an intrapartum temperature of $\geq 38^{\circ} \mathrm{C}$ should receive IPA. ${ }^{13}$

In cases where this chemoprophylaxis (IPA) is not given, the organisms may cause urinary tract infection, amnionitis, endometritis, and maternal wound infection. In 1990, a surveillance system on an American population of ten million persons found that $6 \%$ of EOGBS infections resulted in death, while morbidities were mainly due to overwhelming sepsis and to neurologic sequelae of meningitis. ${ }^{5}$

Even in communities where screening for GBS has been implemented and those characterized by high patient care standards, it is reported that the rate of GBS infections, both late and early onset, are affecting about 1.8/1,000 live births, of which there is a $5 \%-20 \%$ case fatality rate. ${ }^{5,12,16}$

At King Abdulaziz Medical City, Riyadh, Kingdom of Saudi Arabia, we have implemented the risk factor approach for IPA administration over the last decade (the study period). However, several cases of neonatal GBS infection have been reported. The aim of this study was to assess important maternal and neonatal risk factors associated with EOGBS disease in infants $<7$ days of age in comparison with a control group. Moreover, we aimed to assess the resulting maternal and neonatal complications within the affected group. To the investigators' knowledge, no such study has previously been done on a Saudi population.

\section{Methods}

We performed a case control study over a 10-year period, between January 1, 2000 and December 31, 2009. The studied cases were defined as neonates $<7$ days of age who were delivered to Saudi women and were hospitalized in the Neonatal Unit at King Abdulaziz Medical City. GBS cases were isolated from a normally sterile site: eg, blood or cerebrospinal fluid, and they were identified through routine microbiology laboratory reporting. The mothers' urine and vaginas were cultured retrospectively at the time of diagnosis if their GBS status was unknown.

Control neonates were identified by reviewing the medical records to allocate an arbitrary sample of two control neonates for each case those control were born to Saudi women within 24 hours from their assigned case and were in the same birth weight and gestational age category according to World Health Organization classifications. The control neonates were eligible for inclusion if they had no clinical evidence of GBS infection during the first 7 days of life.

Medical records of all 99 neonates who developed GBS disease during the study period and their mothers' records were reviewed. Moreover, the medical records of 200 control neonates and their mothers were reviewed.

Data concerning the maternal age, parity, and GBS status (whether positive, negative, or carrier) were collected. The status of "GBS carrier" was given if a positive GBS culture from a vaginal swab was recorded in the maternal records. Data concerning maternal history of previous GBS or intrauterine fetal death were also obtained. Antenatal data on maternal fever, rupture of membranes, IPA, number of vaginal examinations, labor events, fetal heart rate tracing, infections, postdelivery antibiotics, and others were collected. Neonatal data concerning weight, postdelivery complications, antibiotic requirement, surfactant requirement, place of admission, length of hospital stay, and others were obtained.

All data were entered into a database and analyzed and managed using SPSS software version 15 (SPSS, Inc., 
Chicago, IL, USA). Continuous variables were categorized according to clinically relevant cut-off points. Descriptive analyses were carried out by calculating the frequency and percentage for the categorical variables, mean, and standard deviation for continuous variables. Bivariate analyses for the association between different risk factors and the development of neonatal GBS infection were carried out, and $P$-values were calculated using the $\chi^{2}$ test or Student's $t$-test, as appropriate. Odds ratios (OR) and 95\% confidence intervals $(95 \% \mathrm{CI})$ were calculated for categorical variables, as well as for categorized continuous variables. For the risk factors, adjusted OR and $95 \% \mathrm{CI}$ were calculated. A $P$-value less than 0.05 was considered statistically significant. Stepwise multiple logistic regression was performed to identify the most significant risk factors for the development of EOGBS disease.

Research and ethics committee approvals were obtained through the King Abdullah International Medical Research Center (KAIMRC) prior to conducting the study. No data identifying the neonates or mothers were recorded, and the data forms were kept in a secure place accessible only to the principal and co-investigators.

\section{Results}

Table 1 shows the maternal outcomes and their pregnancy, intrapartum, and postpartum characteristics. It appears from the presented results that mothers of affected babies tend to have a higher body mass index $(P=0.02)$ and shorter duration of pregnancy $(P<0.01)$ and are less likely to receive antenatal care services $(\mathrm{OR}=0.34$, CI 0.19-0.61, and $P<0.01)$. Mothers of neonates who developed EOGBS disease had a stronger history of having previous babies with GBS disease ( $P=0.004)$ and fetuses who had intrauterine fetal death (OR =3.97, CI 1.29-12.19, and $P=0.01)$. Mothers who are GBS carriers are at higher risk of having neonates with GBS infection $(\mathrm{OR}=3.22$, CI 1.54-6.74, and $P=0.001)$, whereas mothers with GBS bacteriuria have a higher risk of delivering a baby who will develop EOGBS disease (OR $=10.76$, CI 1.24-93.42, and $P=0.008$ ).

The intrapartum events of mothers who carried neonates who developed GBS disease in comparison with their controls are shown in Table 1 . These patients were more likely to have a temperature of $\geq 38^{\circ} \mathrm{C}$ during labor ( $\mathrm{OR}=7.10$, CI 2.50-20.17, and $P<0.01)$ and were more likely to have premature rupture of membranes $(\mathrm{OR}=11.99$, CI 6.74-21.36, and $P<0.01)$. They were at higher risk of receiving antibiotic in labor $(\mathrm{OR}=3.92$, CI 2.29-6.71, and $P<0.01)$ and were more likely to be exposed to invasive procedures such as fetal scalp blood sampling and fetal scalp electrode introduction $(P<0.01)$. Moreover, these mothers were exposed to frequent vaginal examinations $(P<0.01)$ and were at higher risk of undergoing operative deliveries $(\mathrm{OR}=1.98$, CI 1.07-3.68, and $P=0.03$ ) compared with their controls.

Mothers of babies who were affected with EOGBS disease were at increased risk of developing postpartum infections $(\mathrm{OR}=8.92$, CI 2.87-27.68, and $P<0.01)$ and had a higher tendency to require antibiotics during the postpartum period $(\mathrm{OR}=2.12$, CI 1.16-3.89, and $P=0.01)$.

Table 2 shows the characteristics and outcomes of neonatal GBS infection. In this table we have identified that neonates who developed EOGBS disease were at an increased risk to have fetal distress ( $O R=5.31$, CI 3.14-8.99, and $P<0.01$ ) and had a higher tendency to have lower birth weight, less length, frequent admission to the neonatal intensive care unit, and a longer stay in the hospital $(P<0.01)$.

These neonates were at increased risk of developing respiratory distress syndrome compared with their controls $(\mathrm{OR}=28.90$, CI 15.00-55.69, and $P=0.0001)$. They were at higher risk of requiring oxygen supply (OR $=32.63$, CI 16.73-63.66, and $P=0.0001)$ and were more prone to requiring continuous airway pressure $(\mathrm{OR}=42.19$, CI 14.51-122.67, and $P=0.0001)$. They were also at a higher risk of requiring assisted ventilation $(\mathrm{OR}=38.56$, CI 11.47-129.60, and $P<0.001)$ and surfactant treatment $(\mathrm{OR}=18.02$, CI 4.03-80.57, and $P=0.0001)$ and of developing convulsions $(\mathrm{OR}=45.11, \mathrm{CI} 5.92-343.67$, and $P=0.0001)$. Finally, these neonates required more tube feedings compared with their controls $(\mathrm{OR}=38.56$, CI 11.47-129.60, and $P=0.0001$ ) and were at higher risk of developing fetal tachycardia (OR $=8.05$, CI 3.30-19.62, and $P<0.01$ ).

Stepwise multiple logistic regression was performed (Table 3). All significant variables that were identified as potential risk factors for the development of neonatal EOGBS disease were included. The three risk factors that were associated with a higher tendency for the development of EOGBS were lack of antenatal attendance $(\mathrm{OR}=0.30, \mathrm{CI}$ $0.98-0.88$, and $P=0.03)$, ruptured membranes $(\mathrm{OR}=9.62, \mathrm{CI}$ 3.1-29.4, and $P=0.0001)$, and antibiotics in labor $(\mathrm{OR}=0.16$, CI 0.38-0.67, and $P=0.013$ ).

\section{Discussion}

The maternal factors identified to increase the risk of neonatal EOGBS disease in this study correspond with earlier international published reports. ${ }^{2-4,6}$ However, this research carries the advantage of assessing the presence of these 
Table I Maternal outcomes and their pregnancy, intrapartum, and postpartum characteristics

\begin{tabular}{|c|c|c|c|c|}
\hline & Cases $(n=99)$ & Control $(n=200)$ & OR $(95 \% \mathrm{CI})$ & $P$-value \\
\hline \multicolumn{5}{|l|}{ Age (years) } \\
\hline Mean \pm SD & $28.2 \pm 7.8$ & $28.4 \pm 5.6$ & NA & 0.84 \\
\hline \multicolumn{5}{|l|}{ Weight (kg) } \\
\hline Mean \pm SD & $79.4 \pm 15.6$ & $78.4 \pm 8.6$ & NA & 0.48 \\
\hline \multicolumn{5}{|l|}{ Height (cm) } \\
\hline Mean \pm SD & $157.7 \pm 5.8$ & $160.3 \pm 5.5$ & NA & $<0.01$ \\
\hline \multicolumn{5}{|l|}{ BMI $\left(\mathrm{kg} / \mathrm{m}^{2}\right)$} \\
\hline Mean \pm SD & $31.8 \pm 5.1$ & $30.5 \pm 2.6$ & NA & 0.02 \\
\hline \multicolumn{5}{|l|}{ Gravida } \\
\hline Mean \pm SD & $5.1 \pm 2.7$ & $4.6 \pm 2.3$ & NA & 0.15 \\
\hline \multicolumn{5}{|l|}{ Parity } \\
\hline Mean \pm SD & $3.2 \pm 3.1$ & $3.1 \pm 2.6$ & NA & 0.07 \\
\hline \multicolumn{5}{|c|}{ Number of live births } \\
\hline Mean \pm SD & $2.5 \pm 2.6$ & $2.5 \pm 2.3$ & NA & 0.97 \\
\hline \multicolumn{5}{|c|}{ Gestational age at birth } \\
\hline Mean \pm SD & $36.3 \pm 3.8$ & $38.5 \pm 2.0$ & NA & $<0.01$ \\
\hline \multicolumn{5}{|c|}{ Previous baby with GBS } \\
\hline Yes & $4(4 \%)$ & $0(0 \%)$ & NA & 0.004 \\
\hline \multicolumn{5}{|c|}{ ANC attendance (booking) } \\
\hline Yes & $64(65 \%)$ & 169 (85\%) & $0.34(0.19-0.61)$ & $<0.01$ \\
\hline \multicolumn{5}{|c|}{ Previous fetal death } \\
\hline Yes & $9(9 \%)$ & $5(3 \%)$ & $3.97(1.29-12.19)$ & 0.01 \\
\hline \multicolumn{5}{|l|}{ GBS carrier } \\
\hline Yes & $19(19 \%)$ & 14 (7\%) & $3.22(1.54-6.74)$ & 0.001 \\
\hline \multicolumn{5}{|c|}{ GBS bacteriuria } \\
\hline Yes & $5(5 \%)$ & I (0.5\%) & $10.76(1.24-93.42)$ & 0.008 \\
\hline \multicolumn{5}{|c|}{ Intrapartum temp $\geq 38^{\circ}$} \\
\hline Yes & $15(15 \%)$ & $5(3 \%)$ & $7.10(2.50-20.17)$ & $<0.01$ \\
\hline \multicolumn{5}{|c|}{ Maximum intrapartum temperature } \\
\hline Mean \pm SD & $37.3 \pm 0.6$ & $37.0 \pm 0.4$ & & $<0.01$ \\
\hline \multicolumn{5}{|l|}{ RM } \\
\hline Yes & $66(68 \%)$ & $30(15 \%)$ & $11.99(6.74-21.36)$ & $<0.01$ \\
\hline \multicolumn{5}{|c|}{ Duration of RM (hours) } \\
\hline Mean \pm SD & $10.7 \pm 16$ & $5.3 \pm 4.9$ & & $<0.01$ \\
\hline \multicolumn{5}{|c|}{ Antibiotic in labor } \\
\hline Yes & 45 (45\%) & $36(18 \%)$ & $3.92(2.29-6.7 I)$ & $<0.01$ \\
\hline \multicolumn{5}{|c|}{ No of vaginal examinations } \\
\hline Mean \pm SD & $6.1 \pm 3.5$ & $3.5 \pm 2.0$ & & $<0.01$ \\
\hline \multicolumn{5}{|c|}{ Mode of delivery } \\
\hline NSVD & $74(75 \%)$ & $172(86 \%)$ & $1.98(1.07-3.68)$ & 0.03 \\
\hline Operative & $23(23 \%)$ & $27(14 \%)$ & & \\
\hline \multicolumn{5}{|c|}{ Maternal infection PP } \\
\hline Yes & $15(15 \%)$ & $4(2 \%)$ & $8.92(2.87-27.68)$ & $<0.01$ \\
\hline \multicolumn{5}{|c|}{ Maternal PP antibiotics } \\
\hline Yes & $25(25 \%)$ & $28(14 \%)$ & $2.12(1.16-3.89)$ & 0.01 \\
\hline
\end{tabular}

Abbreviations: ANC, antenatal care; BMI, body mass index; Cl, confidence interval; GBS, group B streptococcus; NA, not applicable; NSVD, normal spontaneous vaginal delivery; OR, odds ratio; PP, postpartum; RM, ruptured membranes; SD, standard deviation.

factors in a specific, understudied, geographic population in Saudi Arabia.

Our data concluded that the identification of some antenatal and intrapartum factors affecting pregnant women, particularly rupture of membranes, antenatal care services provided, and the use of antibiotics during labor, may predict women whose neonates are at risk of developing EOGBS disease.

Our figures do not differ from other studies; ${ }^{17-23}$ however, they were focusing more on specific risk factors recognized to be more unique to our studied population. For example, in a study from London, UK, women of black ethnic origin 
Table 2 Characteristics and outcomes of neonatal group B streptococcal infection

\begin{tabular}{|c|c|c|c|c|}
\hline & Cases $(n=99)$ & Control $(n=200)$ & OR $(95 \% \mathrm{Cl})$ & $P$-value \\
\hline \multicolumn{5}{|l|}{ Sex } \\
\hline Male & 47 (47\%) & $112(56 \%)$ & $1.34(0.8 \mathrm{I}-2.20)$ & 0.25 \\
\hline Female & $46(46 \%)$ & $82(4 \mid \%)$ & & \\
\hline \multicolumn{5}{|c|}{ CTG with fetal distress } \\
\hline Yes & $59(60 \%)$ & $45(23 \%)$ & $5.31(3.14-8.99)$ & $<0.01$ \\
\hline \multicolumn{5}{|c|}{ Fetal tachycardia $(>160 / \mathrm{min})$} \\
\hline Yes & $22(22 \%)$ & $7(4 \%)$ & $8.05(3.30-19.62)$ & $<0.01$ \\
\hline \multicolumn{5}{|c|}{ Fetal scalp electrode } \\
\hline Yes & $53(54 \%)$ & $43(22 \%)$ & $4.37(2.59-7.37)$ & $<0.01$ \\
\hline \multicolumn{5}{|c|}{ Fetal scalp blood sampling } \\
\hline Yes & $12(12 \%)$ & $0(0 \%)$ & NA & NA \\
\hline \multicolumn{5}{|c|}{ Baby weight (kg) } \\
\hline Mean \pm SD & $2.9 \pm 0.7$ & $3.2 \pm 0.5$ & NA & $<0.01$ \\
\hline \multicolumn{5}{|c|}{ Baby length $(\mathrm{cm})$} \\
\hline Mean \pm SD & $49.0 \pm 3.8$ & $50.6 \pm 1.4$ & NA & $<0.01$ \\
\hline \multicolumn{5}{|l|}{ Days in NICU } \\
\hline Mean \pm SD & $9.7 \pm 10.3$ & $0.3 \pm 2.4$ & NA & $<0.01$ \\
\hline \multicolumn{5}{|c|}{ Days in the hospital } \\
\hline Mean \pm SD & $18.0 \pm 13.8$ & $2.1 \pm 5.3$ & NA & $<0.01$ \\
\hline \multicolumn{5}{|c|}{ Age at diagnosis (days) } \\
\hline Mean \pm SD & $3.1 \pm 1.4$ & NA & NA & NA \\
\hline \multicolumn{5}{|c|}{ Respiratory distress } \\
\hline Yes & $75(76 \%)$ & $21(11 \%)$ & $28.90(15.00-55.69)$ & $<0.0001$ \\
\hline \multicolumn{5}{|c|}{ Oxygen requirement } \\
\hline Yes & $77(78 \%)$ & $21(11 \%)$ & $32.63(16.73-63.66)$ & $<0.0001$ \\
\hline \multicolumn{5}{|l|}{ CPAP } \\
\hline Yes & 45 (45\%) & $4(2 \%)$ & $42.19(14.5 \mid-122.67)$ & $<0.0001$ \\
\hline \multicolumn{5}{|c|}{ Assisted ventilation } \\
\hline Yes & $36(36 \%)$ & $3(1.5 \%)$ & $38.56(11.47-129.60)$ & $<0.0001$ \\
\hline \multicolumn{5}{|l|}{ Nitric oxide } \\
\hline Yes & $12(12 \%)$ & I (0.5\%) & $27.95(3.58-218.39)$ & $<0.0001$ \\
\hline \multicolumn{5}{|l|}{ Surfactant } \\
\hline Yes & $15(15 \%)$ & $2(1 \%)$ & I8.02 (4.03-80.57) & $<0.0001$ \\
\hline \multicolumn{5}{|l|}{ Convulsions } \\
\hline Yes & $18(18 \%)$ & I $(0.5 \%)$ & $45.11(5.92-343.67)$ & $<0.0001$ \\
\hline \multicolumn{5}{|l|}{ Tube feeding } \\
\hline Yes & $36(36 \%)$ & $3(1.5 \%)$ & $38.56(11.47-129.60)$ & $<0.0001$ \\
\hline \multicolumn{5}{|c|}{ Proven sites of colonization } \\
\hline \multicolumn{5}{|l|}{ Sepsis } \\
\hline Yes & 35 (35\%) & I (0.5\%) & & 0.70 \\
\hline \multicolumn{5}{|l|}{ Pneumonia } \\
\hline Yes & $20(20 \%)$ & I (0.5\%) & & \\
\hline \multicolumn{5}{|l|}{ Meningitis } \\
\hline Yes & $4(4 \%)$ & $0(0 \%)$ & & \\
\hline Focal & & & & \\
\hline Yes & 37 (37\%) & $0(0 \%)$ & & \\
\hline All of the abov & & & & \\
\hline Yes & I (I.0\%) & $0(0 \%)$ & & \\
\hline
\end{tabular}

Abbreviations: $\mathrm{Cl}$, confidence interval; CPAP, continuous positive airway pressure; CTG, cardiotocogram; NICU, neonatal intensive care unit; OR, odds ratio; SD, standard deviation.

and those with multiple pregnancies were shown to have an increased risk of delivering an infant with EOGBS disease. ${ }^{19}$ In our work we did not include ethnicity as a risk factor, as we were dealing with a homogeneous Saudi population. In a Swedish study, maternal obesity and overweight were shown to be risk factors associated with increased development of EOGBS disease. ${ }^{24} \mathrm{~A}$ British-based case control study of GBS infection has concluded that antenatal isolation of GBS from vaginal culture, prematurity, prelabor rupture of membranes, and intrapartum fever were all significantly 
Table 3 Multiple logistic regression identifying the most important risk factors associated with the development of earlyonset group B streptococcal disease

\begin{tabular}{llll}
\hline Maternal risk factors & OR & $\mathbf{9 5 \% ~ C l}$ & $\mathbf{P}$-value \\
\hline Antenatal care provided & 0.30 & $0.09-0.89$ & 0.03 \\
Ruptured membranes & 9.62 & $3.15-29.42$ & 0.0001 \\
Antibiotics during labor & 0.16 & $0.38-0.67$ & 0.013 \\
\hline
\end{tabular}

Abbreviations: $\mathrm{Cl}$, confidence interval; $\mathrm{OR}$, odds ratio.

associated with development in cases ${ }^{20}$ corresponding with our initial findings.

It is of concern to note that less than half of the mothers with one or more risk factors received IPA in this study. We may explain this by physicians' poor adherence to the local guidelines, unknown GBS status, or due to false-negative antenatal culture screening results. A British-based audit revealed a variability in the reported practices, ${ }^{25}$ and surveillance data from the Health Protection Agency showed that rates of EOGBS bacteremia have increased, ${ }^{26}$ suggesting the need to reappraise the existing guidelines and their implementation.

Our work, as with other studies, ${ }^{19,20,25}$ emphasizes that the majority of EOGBS infections present in the first 24 hours of life (63.9\%). In a case control study that included 138 cases and 305 controls, ${ }^{27}$ it was indicated that the majority of cases (74\%) presented in the first week of life, and $89 \%$ of them occurred during the first day of life.

EOGBS disease may have contributed to the increased morbidity between both mothers and their neonates. Our affected neonates were more likely to require surgical intervention during labor, to be distressed, and to require more diagnostic invasive procedures compared with their matched controls. Moreover, mothers of neonates with GBS were more likely to develop peripartum infection and were more likely to require antibiotics during labor. Therefore, potential interventions to prevent neonatal GBS infection, such as IPA or GBS vaccination, may contribute to the reduction of both fetal and neonatal morbidities. ${ }^{27}$

Potential limitations of our study are antenatal swabbing to detect carriage of GBS, and the indications for performing this test were not standardized but were left to the physician's own initiative. Moreover, this research has studied the immediate outcome of EOGBS infections and did not approach the maternal and neonatal long-term complications, an area for potential future research.

\section{Conclusion}

A number of maternal and neonatal factors are significantly associated with EOGBS disease. Working on these factors from a preventive aspect may help in better utilization of hospital resources, decrease maternal and neonatal morbidities and mortalities, and decrease their hospital stay. Further study is needed to follow the trends of EOGBS disease among infants after the implementation of a GBS screening program and selective IPA to high-risk mothers.

\section{Disclosure}

The authors report no conflicts of interest in this work.

\section{References}

1. Stoll BJ, Hansen NI, Sanchez PJ, et al. Early onset neonatal sepsis: the burden of group B Streptococcal and E. coli disease continues. Pediatrics. 2011;127(5):817-826.

2. Schuchat A. Group B streptococcus. Lancet. 1999;353(9146):51-56.

3. Schuchat A, Deaver-Robinson K, Plikaytis BD, Zangwill KM, Mohle-Boetani J, Wenger JD. Multistate case-control study of maternal risk factors for neonatal group B streptococcal disease. The Active Surveillance Study Group. Pediatr Infect Dis J. 1994;13(7): 623-629.

4. Boyer KM, Gotoff SP. Strategies for chemoprophylaxis of GBS earlyonset infections. Antibiot Chemother. 1985;35:267-280.

5. Zangwill KM, Schuchat A, Wenger JD. Group B streptococcal disease in the United States, 1990: report from a multistate active surveillance system. MMWR CDC Surveill Summ. 1992;41(6):25-32.

6. Schuchat A, Oxtoby M, Cochi S, et al. Population-based risk factors for neonatal group B streptococcal disease: results of a cohort study in metropolitan Atlanta. J Infect Dis. 1990;162(3):672-677.

7. Carstensen H, Christensen KK, Grennert L, Persson K, Polberger S. Early-onset neonatal group B streptococcal septicaemia in siblings. J Infect. 1988;17(3):201-204.

8. Pass MA, Gray BM, Khare S, Dillon HC Jr. Prospective studies of group B streptococcal infections in infants. J Pediatr. 1979;95(3): 437-443.

9. Moller M, Thomsen AC, Borch K, Dinesen K, Zdravkovic M. Rupture of fetal membranes and premature delivery associated with group B streptococci in urine of pregnant women. Lancet. 1984;2(8394): 69-70.

10. Liston TE, Harris RE, Foshee S, Null DM Jr. Relationship of neonatal pneumonia to maternal urinary and neonatal isolates of group B streptococci. South Med J. 1979;72(11):1410-1412.

11. Persson K, Christensen KK, Christensen P, Forsgren A, Jorgensen C, Persson PH. Asymptomatic bacteriuria during pregnancy with special reference to group B streptococci. Scand J Infect Dis. 1985;17(2): 195-199.

12. Baker CJ. Group B streptococcal infections. Clin Perinatol. 1997;24(1): 59-70.

13. Schrag S, Gorwitz R, Fultz-Butts K, Schuchat A. Prevention of perinatal group B streptococcal disease. Revised guidelines from CDC. $M M W R$ Recomm Rep. 2002;51(RR-11):1-22.

14. Jakobi P, Goldstick O, Sujov P, Itskovitz-Eldor J. New CDC guidelines for prevention of perinatal group B streptococcal disease. Lancet. 1996;348(9032):969.

15. American College of Obstetricians and Gynecologists. ACOG Committee Opinion: number 279, Dec 2002. Prevention of earlyonset group B streptococcal disease in newborns. Obstet Gynecol. 2002;100(6):1405-1412.

16. Weisman LE, Stoll BJ, Cruess DF, et al. Early-onset group B streptococcal sepsis: a current assessment. J Pediatr. 1992;121(3): 428-433.

17. Benitz WE, Gould JB, Druzin ML. Risk factors for early-onset group B streptococcal sepsis: estimation of odds ratios by critical literature review. Pediatrics. 1999;103(6):e77. 
18. Heath PT, Balfour G, Weisner AM, et al. Group B streptococcal disease in UK and Irish infants younger than 90 days. Lancet. 2004; 363(9405):292-294.

19. Mifsud AJ, Efstratiou A, Charlett A, McCartney AC, Health Protection Agency Group BSWG. Early-onset neonatal group B streptococcal infection in London: 1990-1999. BJOG. 2004;111(9):1006-1011.

20. Oddie S, Embleton ND. Risk factors for early onset neonatal group B streptococcal sepsis: case-control study. BMJ. 2002;325(7359):308.

21. Moses LM, Heath PT, Wilkinson AR, Jeffery HE, Isaacs D. Early onset group B streptococcal neonatal infection in Oxford 1985-1996. Arch Dis Child Fetal Neonatal Ed. 1998;79(2):F148-F149.

22. Halliday E, Foote K, Dryden M, Heard M, Down R, Ward J. Universal maternal screening for neonatal group B streptococcal disease. Lancet. 2000;356(9239):1407-1408.

23. Beardsall K, Thompson MH, Mulla RJ. Neonatal group B streptococcal infection in South Bedfordshire, 1993-1998. Arch Dis Child Fetal Neonatal Ed. 2000;82(3):F205-F207.
24. Hakansson S, Kallen K. High maternal body mass index increases the risk of neonatal early onset group B streptococcal disease. Acta Paediatr. 2008;97(10):1386-1389.

25. Cromwell D, Joffey T, Van der Meulen J. The Prevention of Early-onset Neonatal Group B Streptococcal Disease in UK Obstetric Units: An Audit of Reported Practice in England, Scotland, Wales and North Ireland. London, UK: Royal College of Obstetricians and Gynaecologists; 2007.

26. Health Protection Agency. Pyogenic and Non-pyogenic Streptococcal Bacteraemias, England, Wales and Northern Ireland: 2006. London, UK: Health Protection Agency; 2007.

27. Heath PT, Balfour GF, Tighe H, Verlander NQ, Lamagni TL, Efstratiou A; HPA GBS Working Group. Group B streptococcal disease in infants: a case control study. Arch Dis Child. 2009;94(9):674-680.
International Journal of Women's Health

\section{Publish your work in this journal}

The International Journal of Women's Health is an international, peerreviewed open-access journal publishing original research, reports, editorials, reviews and commentaries on all aspects of women's healthcare including gynecology, obstetrics, and breast cancer. The manuscript management system is completely online and includes

\section{Dovepress}

a very quick and fair peer-review system, which is all easy to use. Visit http://www.dovepress.com/testimonials.php to read real quotes from published authors.

\footnotetext{
Submit your manuscript here: http://www.dovepress.com/international-journal-of-womens-health-journal
} 